\title{
Da biopotência vegetal
}

About vegetal biopotency

Resenha de MARDER, Michael; TONDEUR, Anaiis. Chernóbil herbarium: fragmentos de una conciencia explotada. Barcelona: NED, 2021.

Andityas Soares de Moura Costa Matos*

Ser cientista é ser ingênuo. Focamos tanto na procura pela verdade que não consideramos que poucos querem que a encontremos. Mas ela está sempre lá, quer a vejamos ou não, escolhamos ou não. A verdade não se importa com o que queremos. Não se importa com nossos governos, ideologias, religiões. Ela ficará à espera para sempre. E isto, por fim, é a dádiva de Chernobil. Já temi o preço da verdade, mas agora apenas pergunto: qual é o preço das mentiras?

Chernobyl

O magnífico livro Chernóbil herbarium: fragmentos de una conciencia explotada, que a editora espanhola NED lançou em abril deste ano, é composto por trinta e cinco fragmentos filosóficos - um para cada ano contado a partir do desastre nuclear de Tchernóbil em 1986 - escritos por Michael Marder, filósofo de origem russa e hoje professor no País Basco, acompanhados por fotogramas de Anaiis Tondeur, artista visual francesa. Essas obras de arte foram criadas a partir das plantas cultivadas na zona de exclusão de Tchernóbil, hoje na Ucrânia, por Martin Hajduch, do Instituto de Genética de Plantas e Biotecnologia da Academia Eslovaca de Ciências, conformando assim um híbrido texto-imagem que, apesar de ser "uma espécie de testemunho que guarda um absoluto silêncio" (p. 17), grita diante de nós.

Conheci Michael Marder em um congresso sobre Carl Schmitt na cidade de Uberlândia em 2012. Entre uma palestra e outra, sob um sol escaldante, acabamos conversando sobre outros temas, de modo que Michael me falou sobre sua pesquisa em filosofia sobre as plantas. Naquela altura eu achei muito estranho alguém se dedicar a pensar filosoficamente os vegetais, dado que, por definição, a filosofia tem a ver com o pensamento, justamente o que falta a esses seres. Eu não sabia, contudo, que essa minha opinião era fruto de um poderoso preconceito aristotélico, que classifica hierarquicamente os seres vivos e coloca as plantas no mais baixo grau, daí derivando a expressão "vida vegetativa" que, aplicada a seres humanos, indica a ausência de qualquer função "nobre" no organismo, tal como o raciocínio, referindo-se portanto à manutenção da mera vida.

Anos depois dessa conversa com Michael, acabei me interessando pela filosofia
Este é um artigo publicado em acesso aberto (Open Access) sob a licença Creative Commons Attribution, que permite uso, distribuição e reprodução em qualquer meio, sem restrições desde que sem fins comerciais e que o trabalho original seja corretamente citado.

\footnotetext{
* Doutor em Direito e Justiça pela Universidade Federal de Minas Gerais. Pós-Doutor em Filosofia do Direito pela Universitat de Barcelona. Doutor em Filosofia pela Universidade de Coimbra. Professor Associado de Filosofia do Direito e disciplinas afins na UFMG. Autor de Filosofia radical e utopias da inapropriabilidade: uma aposta an-árquica na multidão (Fino Traço, 2015) e Representação política contra democracia radical: uma arqueologia (a)teológica do poder separado (Fino Traço, 2019). Coautor, com Francis García Collado, de Mas allá de la biopolítica: biopotencia, bioarztquía, bioemergencia (Documenta Universitaria, 2020) e $O$ vírus como filosofia/A filosofia como vírus: reflexões de emergência sobre a COVID-19 (GLAC, 2020).E-mails: vergiliopublius@hotmail.com e andityas@ufmg.br. Mais artigos em: https://ufmg.academia.edu/AndityasSoares
} 
das plantas no contexto de meus estudos sobre biopotência, em especial considerando as instigantes obras de autores como Emanuele Coccia e Stefano Mancuso, entre outros. A partir daí, um novo universo se abriu para mim e descobri que as plantas são talvez os seres mais filosóficos que existem. Tratase, com efeito, de formas de vida muito antigas e extremamente potentes tendo em vista suas capacidades de transformação, disseminação, regeneração e automanutenção. A antiga palavra grega arkhé, que para os pré-socráticos indicava $\circ$ princípio fundamental de toda a realidade, se aplica perfeitamente aos vegetais, pois tal termo evoca ao mesmo tempo algo muito antigo e muito poderoso, dele derivando palavras como "arquiteto", "monarquia", "arcaico" etc. Sem dúvida, as plantas são não apenas nossa arkhé, recordando em suas próprias bioestruturas um longo passado compartilhado que esquecemos, mas também apontam para nosso futuro, pois nada melhor do que um vegetal para nos ensinar as artes da mutação, da cooperação e da singularização. Assim, a visão aristotélica que eu tinha desses seres se transformou. Se antes o caráter "básico" das plantas indicava seu nível elementar na dinâmica da complexidade da vida, prefiro agora entender esse adjetivo de maneira literal e radical, vendo nas plantas a base da vida, ou seja, da dimensão biopotente que nos sustenta e nos mantém.

Hoje são desenvolvidos muitos estudos filosóficos que exploram 0 caráter "arcaico" - ou seja, fundador e potente - das plantas, o que quase sempre envolve afetos alegres, para usar uma expressão de Deleuze. Raramente o que chamo de "filosofia das plantas" se orienta com base em afetos tristes, e aí está a primeira das muitas diferenças do livro Chernóbil herbarium, pois desde o título se anuncia um pensamento que tem como pano de fundo o terrível acidente nuclear de Tchernóbil, cujo marco inicial se deu em 26 de abril de 1986. Contudo, - livro não se compõe de lamentos, estruturando-se antes como um potente dispositivo filo-imagético em que a negatividade comparece para ser transvalorada e assumida a partir de uma sensibilidade que, não sendo (totalmente) antropocêntrica e sim vegetal, põe em xeque as díades que separam alegria e tristeza, bem e mal, comédia e tragédia. $E$ isso porque, como disse Heidegger, lá onde está o perigo, está também o que salva.

Não deixa de ser irônico citar aqui o pensador que em nosso tempo foi talvez - que menos compreendeu as plantas, classificando-as como "pobres de mundo", dado que, segundo entendia o alemão, no "aí" $(D a)$ delas não se abre a possibilidade da linguagem. Com Michael Marder podemos questionar esse juízo tão estreito, partindo de uma compreensão muito diferente da linguagem, eis que as plantas que agora florescem nos campos - uso esta palavra no terrível sentido que the deu Giorgio Agamben - radioativos de Tchernóbil e arredores desenvolvem um tipo muito específico de linguagem e têm muito a nos dizer sobre mudanças, resistência e esperança, algo mais do que urgente em um tempo de catástrofe universal como o nosso. Com efeito, muitos de nós acreditam que não vão sobreviver às mudanças climáticas, aos vírus vindouros semelhantes ao novo corona, ao nojo crescente com o mundo e o ressurgimento do fascismo patrocinado por figuras como Bolsonaro e Trump. Sem diminuir a importância desses eventos sinistros, precisamos lê-los dentro de um contexto mais amplo e compreender que a força mutante e impessoal da vida encontra 
seus caminhos para se afirmar diante da pulsão de morte. O fato de plantas germinarem e crescerem nos campos de Tchernóbil, passados apenas 35 anos do acidente nuclear, indica que há uma potência vital no planeta que não vai ser vencida assim tão facilmente e que é a ela que devemos nos conectar.

A mescla entre texto e imagem em Chernóbil herbarium é surpreendente: em um ritmo fluído, Marder evoca alguns dos temas centrais de seu percurso filosófico e os irmana a esses fotogramas que, em suas palavras, "traduzem exposição como expressão, e vulnerabilidade como uma forma de testemunho" (p. 42). Os trabalhos de Tondeur, parece-me necessário esclarecer desde logo, não são fotografias - esse tipo de "escrita da luz" - e sim fotogramas criados a partir da longa exposição das plantas de Tchernóbil diante de papel fotossensível, conformando algo similar a uma captura da "aura" do vegetal. Graças à generosidade da artista, publicamos cinco de seus fotogramas ao longo desta edição da (Des)troços. Por seu turno, integrados por reflexões pessoais, estéticas, políticas e filosóficas, os textos do livro não desenvolvem propriamente uma tese geral, tendo em vista o caráter impensável e irrepresentável do evento de que parte, e por isso mesmo só podem dar lugar a uma ética, ou seja, a um éthos do singular que se põe enquanto divergência diante das estruturas "racionais" que conformam nossa cultura. Nesse sentido, a bem urdida prosa filosófica de Marder torna possível um mergulho em realidades nas quais a consciência não se confunde com o ego cartesiano ou 0 self pós-moderno, constituindo antes uma rede autoprodutiva e autorrecursiva, similar àquela já pensada pelos estoicos gregos, mediante a qual se percebe que a biosfera constitui um único ser vivo.
Segundo Marder, as plantas têm consciência e muitas coisas a nos dizer. Nesse sentido, a verdade a que se refere - químico Valery Legasov na última sequência da excelente minissérie da HBO Chernobyl e que serve de epígrafe desta resenha, pode ser compreendida de uma maneira bastante óbvia, dado que, se plantas conseguem se desenvolver hoje na zona de exclusão de Tchernóbil, isso parece indicar a evidência sublinhada por Claude LéviStrauss, para quem o mundo surgiu sem o ser humano e vai terminar sem ele. Todavia, podemos ir além do óbvio e, quiçá, transformá-lo, mutá-lo.

Ainda que o livro se construa mediante elementos de vários saberes e a linguagem de Marder seja clara e acessível, o que temos diante de nós é um pequeno tratado de metafísica que, centralizado na dimensão invisível da tragédia de Tchernóbil - que continua até hoje, já que as consequências na fauna, na flora e nos humanos não cessaram e, mais importante, o enlouquecido modelo nuclear não foi abandonado -, acerta em cheio ao ver na permanência desse evento a sua dimensão verdadeiramente insuportável. Trata-se então de um pesadelo filosófico, conclui Marder, em que o eterno se põe enquanto repetitiva penalidade infernal que jamais termina e por isso nos impede até mesmo 0 acesso ao luto. Considerando que $\circ$ período de semidesintegração do urânio U-238 presente na zona de exclusão de Tchernóbil é de 4,5 bilhões de anos aproximadamente a idade atual do planeta terra -, a radioatividade letal permanece como herança para uma humanidade perplexa. Assim, já que não conseguimos "digerir" o fenômeno, só nos restaria reconhecer que "os materiais radioativos são os novos excrementos de uma humanidade faminta por energia 
que contamina $\circ$ meio ambiente do porvir" (p. 47).

Contra essa perspectiva se opõe a biopotência das plantas, que nos ensinam que tudo precisa ser decomposto, transformado, absorvido, de modo que se construa um eterno retorno do diferente. É exatamente isso que Tchernóbil não nos permite, ao manter ativos por bilhões de anos seus resquícios, com o que se mostra como o exato símile do capitalismo neoliberal que pretende ser eterno, imutável e sempre presente. Só um pensamento vegetal da mescla e da hibridação, mas também da decomposição, da morte e do luto pode nos abrir novos caminhos. Para tanto, argumenta Marder, parece ser crucial abandonar os dualismos da presença e da eternidade, tão caros à metafísica ocidental, e reconhecer que as plantas também possuem consciência, e isso significa que elas "têm suas próprias formas de conhecimento, sensibilidade, memória, aprendizagem e pensamento" (p. 90). Aceitar essa "subjetividade vegetal" pode então nos auxiliar na necessária tarefa de relativização da arruinada consciência humana, abrindo espaço para outros tipos de pensamento que não estejam centrados no "eu", na propriedade e no domínio do outro. Talvez assim possamos, sugere Marder, chorar a morte da morte (p. 167), essa herança quase eterna que a radioatividade de Tchernóbil e o neoliberalismo nos impõem com seus isótopos mortíferos e suas toneladas de plástico dificilmente biodegradáveis.

Ao compreender que entramos em uma nova dimensão epocal na qual já não podemos sequer experimentar a antecipação da morte aconselhada por Epicuro e Heidegger, seja porque há coisas que não "morrem" (como o U-238), seja porque estamos assediados por uma morte-em-vida, compreendemos também a necessidade de encontrar forças renovadas na antiga arkhé vegetal, capaz de nos mostrar que a vida se diz de muitos modos. Um deles, e um dos mais potentes, se chama comum, já que estamos todos no mesmo barco planetário que ameaça, entre radiações e vírus, naufragar para sempre, e isso significa: nunca parar de naufragar. Mais do que um deus para nos salvar, precisamos construir juntamente com as plantas uma selva selvaggia - e não um paraíso que, como revela a origem avéstica da palavra pairi-daeza, é apenas um "jardim cercado" - que torne possível a mescla, a indeterminação, o gozo e a contínua metamorfose. Só assim desabrocharemos. 